\title{
Six sigma implementation model based on critical success factors (CSFs) for indonesian small and medium industries
}

\author{
Teuku Yuri M. Zagloel ${ }^{1, \mathrm{a}}$, Romadhani Ardi ${ }^{1, \mathrm{~b}}$, and Wahyu Poncotoyo ${ }^{1, \mathrm{c}}$ \\ ${ }^{1}$ Department of Industrial Engineering, Faculty of Engineering, Universitas Indonesia
}

\begin{abstract}
This study aims to build a model of critical success factors in the application of Six Sigma for Indonesian small and medium industries and their relation to the industry performance. The critical success factors, successful Six Sigma implementation and the impact on industry performance are validated and analyzed. The method used in this study is Structural Equation Modeling (SEM) based on Partial Least Square (PLS) by using SmartPLS software. This study uses 54 data from Indonesian small and medium industries that have implemented Six Sigma. The results of this study indicate that a critical success factors that has a positive impact on the successful Six Sigma implementation is the involvement and commitment top management, training and education, cultural change and industrial infrastructure. It is surprising that teamwork has a negative impact on the successful Six Sigma implementation. In addition, the successful Six Sigma implementation has a positive impact on the performance of Indonesian small and medium industries. Then, the model is valid to shows the relationship between critical success factors in the successful Six Sigma implementation on the performance of small and medium industries in Indonesia.
\end{abstract}

\section{Introduction}

In Southeast Asia (ASEAN), Indonesia becomes the country with the highest Gross Domestic Product. In the world, Indonesia's ranking is $16^{\text {th }}$ with the number of Gross Domestic Product at $\$ 932,259$ and then followed by Thailand at $\$ 407,026\left(25^{\text {th }}\right)$, Philippines at $\$ 304,905\left(35^{\text {th }}\right)$, Singapore at $\$ 296,975\left(36^{\text {th }}\right)$, Malaysia at $\$ 296,535\left(37^{\text {th }}\right)$, Vietnam at $\$ 205,279\left(46^{\text {th }}\right)$, Myanmar at $\$ 63,225\left(70^{\text {th }}\right)$, Cambodia at $\$ 20,016\left(106^{\text {th }}\right)$, Laos at $\$ 15,805\left(113^{\text {th }}\right)$, and the last one is Brunei Darussalam at $\$ 11,400\left(125^{\text {th }}\right)$ [1]. Gross Domestic Product is a summary of the number of products produced in a country within a year [2] and is an important variable in analyzing a country's economic growth [3]. As much as $20.51 \%$ of Gross Domestic Product in Indonesia is produced by manufacturing industry [4].

For modern economic today, small and medium industries play an important role in sustaining the economy of a country and even the world economy. "Small and medium

\footnotetext{
${ }^{\mathrm{c}}$ Corresponding Author: wahyu.poncotoyo@ui.ac.id
} 
industries are the source of modern economic life" [5]. In order to keeping their contribution to the modern economic growth, small and medium industries are required to improve production quality to meet the increasingly high market demands and expects high precision levels. On the other hand, a study shows that the success of small and medium industries has a direct impact on economic development in developed and developing countries [6]. They have the ability to produce products with minimum cost, pioneers in the field of innovation and have a high flexibility that enables them to meet customer needs [7]. In 2015 there are 3,385,851 units of small and medium industries in Indonesia [4]. Small, medium and also large industries can be classified on the basis of profits, units of electricity consumed, the amount of labor and considered as machines for economic growth in Europe [8]. In Indonesia the definition of industrial scale is regulated in the regulation of the Minister of Industry number 64 of 2016 [9].

However, when compared to the level of global competitiveness for the year 2016-2017, Indonesia's ranking is $41^{\text {th }}$ [10]. In terms of competitiveness in Southeast Asia (ASEAN), Indonesia should be left behind by Singapore, Malaysia, and Thailand respectively ranked $2^{\text {nd }}, 25^{\text {th }}$, and $34^{\text {th }}$. To improve competitiveness, many ways can be implemented. Increasing productivity is a way to improve competitiveness. In increasing productivity, one way is to do continuous improvement program. With continuous improvement the industry will improve their performance to achieve its goals to meet the consumer needs. As a business strategy, Six Sigma focuses on improving understanding of customer needs, increasing productivity levels, and industry performance [11]. A survey of 2,870 respondents undertaken to examine ongoing improvement programs that provide the best outcomes for industries that implement them. Survey results showed that $53.6 \%$ of respondents chose Six Sigma as the most important program, 26.3\% respondents chose Lean, and $10.3 \%$ of respondents chose Total Quality Management (TQM) [12]. This activity is done by the industry as a form of effort in improving their performance, so that if achieved will have an impact on customer satisfaction. Efficiency, profitability, responsiveness and customer satisfaction have been a major concern of the company [13].

The success rate of implementing Six Sigma for the industry is influenced by several critical success factors. A critical success factor is an important ingredient required for the success of a Six Sigma project within an industry [14]. According to Rungasamy, Antony, and Ghosh (2002), critical success factors are factors needed to ensure success of any initiative or program to be implemented, in other words if the critical factor of success in the implementation of Six Sigma is not achieved, six sigma will fail in the implementation [15]. To implement Six Sigma, top industry management must have an understanding of quality management that builds Six Sigma methodology, in addition to understanding top management should also be involved directly so that the implementation of Six Sigma does not lose the goal because top management understands and participates in the application of Six Sigma [16]. By increasingly demonstrating that successful implementation of Six Sigma methods will affect industry performance [17], this study assumes that industry performance can be an indicator of successful implementation of Six Sigma. So bring up some interesting questions, namely:

1. What is the critical success factors that have a positive impact on the successful implementation of Six Sigma in small and medium industries in Indonesia?

2. Does successful implementation of Six Sigma have a positive impact on the performance of small and medium industries in Indonesia?

3. How is the involvement and commitment of top management as the main foundation of critical success factors in successful implementation of Six Sigma in small and medium industries, influencing other critical success factors? 


\section{Literature review}

According to Tack-Wei Leong and Pee-Lee Tea (2012) in his study concluded that after a thorough review of the critical success factors theories that were important for this study were measured by five factors: involvement and commitment top management, training and education, teamwork, cultural change, and industrial infrastructure [19, 25]. The initial conceptual model in this study builds on a conceptual model of critical success factors in the application of Six Sigma in the OEM or original equipment manufacturing industry in Malaysia [18]. The use of this conceptual model is based on the fact that the model is tested in the industrial sector in developing countries. This model consists of five critical success factors that have also been used in previous research, namely:

1. Involvement and commitment top management. According to many experienced experts, Six Sigma recognizes that involvement and commitment top management are critical success factors [19]. Many previous studies that use this critical success factor, use similar terms, as one of the success factors in the application of Six Sigma. These include top management and leadership commitment [20]; management commitment [21] top management commitment [22], executive engagement [23].

2. Training and Education. Samsung believe that training and education is an important step that companies must take in preparing for the implementation of Six Sigma, enabling companies to establish and create new goals as employees are asked to think and act in different ways [24]. Providing training and education is important in the application of Six Sigma [25]. It is indispensable to plan the application of Six Sigma to continue to grow and not run in place due to limited knowledge [26]. Some studies have used different terms such as: Training [22], education and training [27].

3. Teamwork. This is related to the sharing of knowledge and experience [28]. Teamwork can be defined as the extent to which people in the group actively support and assist one another with their work [29]. There are several terms used and have a single meaning with teamwork that has been used in previous studies including: effective communication [30], team communication [8], as well as team involvement and commitment [31].

4. Cultural Changes. The success of an industry in controlling market share is highly dependent on the industrial working culture [32]. Successful introduction and implementation of Six Sigma requires adjustment to organizational culture and changes in the attitudes of its employees. Employees must be motivated and accept responsibility for the quality of their own work [22]. In the previous studies that use several terms of cultural change include: organizational culture change [33], cultural change [34].

5. Industrial Infrastructure. The importance of this critical success factor has been conveyed by several studies [19, 21, 25, 36]. Critical success factors in the application of Six Sigma are related to Brun's research (2010), Antony and Banuelas (2002), and Tlapa et al, (2016). Some studies use different terms including: organizational infrastructure [35], infrastructure and organizational culture [36].

A research model reveals that Lean Six Sigma has become the most influential quality method for the performance of the automotive industry, especially car manufacturers in their efforts to improve competitiveness, in addition to making those industries able to improve innovation, technology development, quality, production process and customer satisfaction [37]. Good Six Sigma project performance affects industry performance because Six Sigma projects must have some characteristics related to business priorities and are critical to the industry [17]. This is because if the industry has succeeded in implementing Six Sigma there will be defect reduction, cycle time reduction, lot size reduction, and inventory reduction, which will lead to reduced production costs and 
increased customer satisfaction. Measuring industrial performance is generally done in any industry, whether applied to measuring aspects of finance, non-financial aspects, or both. Based on this theory, Kaplan and Norton (1992) proposed several performance measures using a balanced scorecard approach. This comprehensive measure of performance is based on four perspectives: finance, customers, processes or industrial operations, and innovation. Industry performance indicators consist of finance, consumer, internal business, and innovation [38]. The models of Tack-Wei Leong and Pee-Lee Tea (2012) and Habidin and Yusof (2013) were modified to examine relations empirically and obtain models that fit the conditions of small and medium industries in Indonesia. Here are the considerations:

1. Any successful quality method such as Six Sigma requires top management involvement as the provision of appropriate resources and training [39]. The involvement and commitment of top management is recognized as a critical success factor in the successful implementation of Six Sigma by those who have implemented Six Sigma [19]. Jack Welch, General Electric's chief, is heavily involved in restructuring business organizations and changing employee attitudes toward the application of Six Sigma [19]. Therefore, in this study "the involvement and commitment of top management" is the critical success factor that will influence other critical success factors.

2. Semi-structured interviews with three Six Sigma experts are conducted to get a direct picture of the relationship between critical success factors in the application of Six Sigma. Based on the interviews it is found that in this research critical factor of success is the involvement and commitment of top management has an indication of positive relationship to other critical success factors that are: training and education, teamwork, cultural change, and industrial infrastructure. In addition, according to Six Sigma experts, states that by doing training and education about Six Sigma an industry will be more receptive to cultural changes that come in conjunction with the implementation of Six Sigma. Teamwork will be easy to establish and build when employees are trained and educated and openness to new cultures.

Based on these two considerations, the hypothesis on the conceptual model proposed in this study is as follows:

H1. The involvement and commitment of top management has a positive impact on training and education, cultural change, teamwork, industry infrastructure and the successful implementation of Six Sigma.

H2. Training and education have a positive impact on teamwork, cultural change and the successful implementation of Six Sigma.

H3. Teamwork has a positive impact on the successful implementation of Six Sigma.

H4. Cultural changes have a positive impact on teamwork and successful implementation of Six Sigma.

H5. Industrial infrastructure has a positive influence on the successful implementation of Six Sigma.

H6. Successful implementation of Six Sigma has a positive influence on industry performance. 


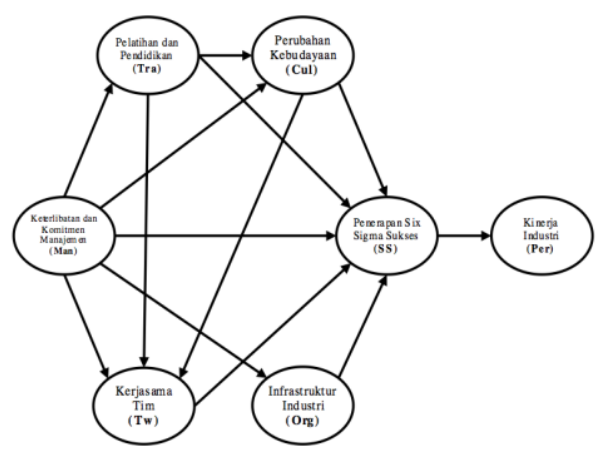

Fig. 1. The Conceptual model

\section{Research methodology}

In this study, there are 24 measuring variables obtained through theoretical reviews and interviews with Six Sigma experts. Pilot testing was conducted on ten academics aimed at knowing the clarity of terms used in the questionnaire instrument. Likert scale is worth 1 (strongly disagree) up to 5 (critical) is used to know the respondent's assessment of the questionnaire instrument. This survey was conducted among small and medium-sized industrial companies that have implemented Six Sigma in Indonesia. A total of 60 questionnaires were sent to the respondents and a total of 54 questionnaires were returned. A total of 54 questionnaires are considered valid. Based on the respondents involved in the research, 90 percent are manufacturing industry, 4 percent is construction industry, 2 percent is industry in finance, 2 percent is mining industry, and 2 percent is industry service area. The proportion of industrial scale is 87 percent is medium industry. To estimate the SEM model parameters, this study uses the Partial Least Square (PLS) procedure. PLSSEM provides many advantages for researchers working with structural equation models, such as using non-distributed data, small sample size and research models with formative indicators [40]. According to Barclay et al. (1995), states that the minimum sample size for the PLS model should be equal to greater than: ten times the number of indicators most used to measure a latent variable, or ten times the number of model paths (arrows) directed to a latent variable in inner model [41]. In this study, the minimum number of samples to be achieved is as many as 40 samples. Thus, the sample size in this study is appropriate for use with PLS procedures.

\section{Data analysis}

\subsection{The testing of measurement model}

Manurut Ghozali (2008), in the using PLS-SEM requires two stages to assess the Fit Model of a study. These stages include the stage of analysis or evaluation of measurement models and structural model analysis. There are three criteria in using data analysis techniques with SmartPLS to assess the validity and reliability of the outer model of convergent validity, discriminant validity, and composite reliability.

\subsubsection{Convergent validity}


Convergent validity aims to ensure indicators of latent variables are highly correlated with these variables. Convergent validity can be seen from the weighting factor and Average Variance Extracted (AVE). The measuring variable that has a weighting factor of $>0.5$ is considered very significant [42]. Then for Average Variance Extracted (AVE) must also have value $>0.5$ [43]. Thus, a value of 0.5 is the cutting point used to ensure that measure variables can represent latent variables. In this study, all measure variables had loading factors value $>0.5$ ranging from 0.574 to 0.944 . Thus it can be said that all measure variables can represent latent variables. And then, for Average Variance Extracted (AVE) values is $\mathrm{MAN}=0.696, \mathrm{TRA}=0.740, \mathrm{CUL}=0.729, \mathrm{TW}=0.771, \mathrm{ORG}=0.659, \mathrm{SS}=$ 0.811 , and PER $=0.725$.

\subsubsection{Discriminant Validity}

Discriminant validity ensures that indicators of different latent variables should not be highly correlated [43]. This can be seen from the value of cross loading for each latent variable $>0.5$ [43]. Discriminant validity also sees the square root of AVE ( $\sqrt{ }$ AVE), for each latent variable and compared with the correlation value between latent variables [43]. The rule of thumb of the square root AVE $(\sqrt{ } \mathrm{AVE})$, is the square root $\mathrm{AVE}(\sqrt{\mathrm{AVE}})$, must be greater than the correlation value between the latent variables [43]. Based on the calculation then the overall value of cross loading and square root of AVE ( $\sqrt{ }$ AVE) in accordance with the criteria (see table I).

\subsubsection{Composite Reliability}

Reliability test or internal consistency reliability in PLS can use two parameters that is cronbach's alpha and composite reliability [43].

Table 1. Measure of Discriminant validity (Source: Data Processing Using SmartPLS 3.2.7)

\begin{tabular}{|c|c|c|c|c|c|c|c|c|}
\hline \multirow{2}{*}{ Laten } & & \multicolumn{7}{|c|}{ Nilai Korelasi dengan Variabel } \\
\hline & & Man & Tra & Cul & Tw & Org & SS & Per \\
\hline \multirow{4}{*}{ MAN } & Man1 & 0,868 & 0,778 & 0,753 & 0,852 & 0,815 & 0,837 & 0,818 \\
\hline & Man2 & 0,895 & 0,881 & 0,755 & 0,781 & 0,805 & 0,836 & 0,807 \\
\hline & Man3 & 0,838 & 0,773 & 0,677 & 0,699 & 0,596 & 0,75 & 0,733 \\
\hline & Man4 & 0,73 & 0,695 & 0,629 & 0,588 & 0,613 & 0,729 & 0,571 \\
\hline \multirow{3}{*}{ TRA } & Tra1 & 0,819 & 0,843 & 0,684 & 0,732 & 0,723 & 0,804 & 0,842 \\
\hline & Tra2 & 0,86 & 0,927 & 0,761 & 0,725 & 0,739 & 0,809 & 0,764 \\
\hline & Tra3 & 0,741 & 0,808 & 0,679 & 0,718 & 0,707 & 0,791 & 0,585 \\
\hline \multirow{3}{*}{ CUL } & Cull & 0,788 & 0,722 & 0,89 & 0,786 & 0,739 & 0,805 & 0,82 \\
\hline & Cul2 & 0,813 & 0,832 & 0,884 & 0,832 & 0,745 & 0,83 & 0,749 \\
\hline & $\mathrm{Cul} 3$ & 0,526 & 0,518 & 0,783 & 0,518 & 0,632 & 0,633 & 0,439 \\
\hline \multirow{3}{*}{ TW } & Tw1 & 0,803 & 0,763 & 0,75 & 0,89 & 0,766 & 0,819 & 0,83 \\
\hline & Tw2 & 0,704 & 0,7 & 0,723 & 0,862 & 0,736 & 0,73 & 0,665 \\
\hline & Tw3 & 0,81 & 0,755 & 0,787 & 0,882 & 0,861 & 0,839 & 0,701 \\
\hline \multirow{3}{*}{ ORG } & Org1 & 0,559 & 0,528 & 0,502 & 0,598 & 0,766 & 0,542 & 0,586 \\
\hline & Org2 & 0,626 & 0,647 & 0,671 & 0,716 & 0,828 & 0,699 & 0,548 \\
\hline & Org3 & 0,855 & 0,829 & 0,805 & 0,848 & 0,908 & 0,907 & 0,822 \\
\hline \multirow{4}{*}{ SS } & Ss1 & 0,875 & 0,867 & 0,785 & 0,818 & 0,816 & 0,92 & 0,919 \\
\hline & Ss2 & 0,786 & 0,834 & 0,768 & 0,751 & 0,782 & 0,866 & 0,735 \\
\hline & Ss3 & 0,828 & 0,794 & 0,81 & 0,808 & 0,832 & 0,906 & 0,791 \\
\hline & $\mathrm{Ss} 4$ & 0,914 & 0,858 & 0,856 & 0,891 & 0,83 & 0,915 & 0,818 \\
\hline \multirow{4}{*}{ PER } & Per1 & 0,846 & 0,856 & 0,756 & 0,796 & 0,78 & 0,858 & 0,944 \\
\hline & Per2 & 0,408 & 0,374 & 0,498 & 0,456 & 0,51 & 0,533 & 0,574 \\
\hline & Per3 & 0,804 & 0,72 & 0,711 & 0,771 & 0,71 & 0,821 & 0,922 \\
\hline & Per4 & 0,871 & 0,859 & 0,743 & 0,767 & 0,752 & 0,838 & 0,912 \\
\hline
\end{tabular}




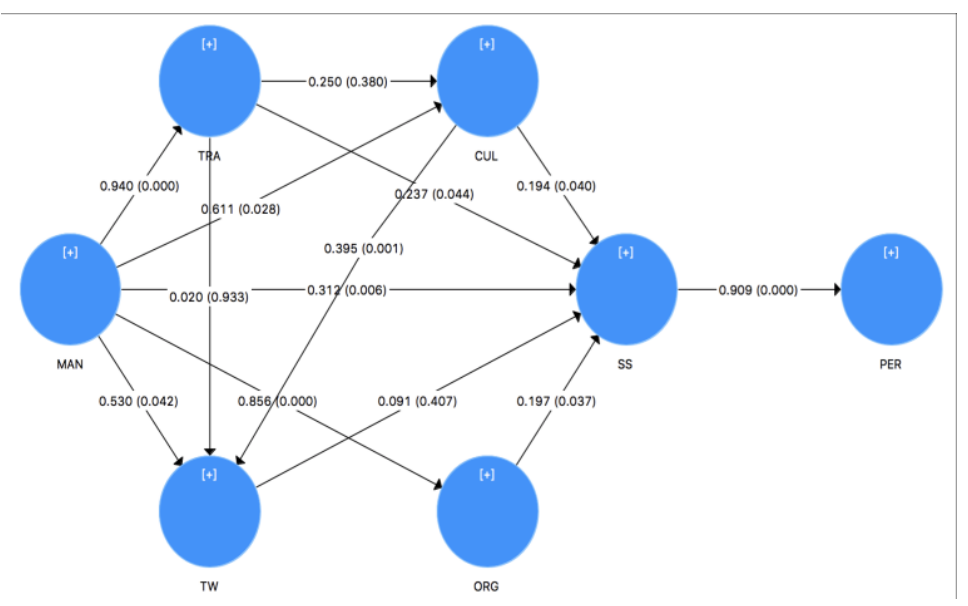

Fig. 2. The Result of Path Coefficient

Note: The value without parentheses is the value of the Path Coefficient and the value inside parentheses is the P-Value.

Cronbach's alpha assumes that all indicators are reliable and composite reliability assumes that indicators have different loading values [44]. Hair et al. (2010) explains that the cut off point for estimating the reliability of a latent variable is 0.7 . Therefore, any latent variant that has a score of $>0.7$ can be said to have good reliability. In this study, all latent variables had values $>0.7$ ranging from 0.739 to 0.922 . Thus it can be said that all latent variables have a good level of reliability so that it can be passed on the next tes

\subsection{The test of structural model}

The evaluation of structural model or inner model aims to predict the relationship between latent variables [43]. the structural model is evaluated by looking at the percentage of variance by looking at R-Square values for endogenous variables, predictive relevance test, and average variance extracted for prediction values using resampling procedures such as jackknifing and bootstrapping in order to stabilize model measurement [43]. There are four criteria to evaluate the structural model, namely coefficient determination (R-Square), path coefficient, Cohen (f2), and predictive relecance (Q2) [44].

\subsubsection{Coefficient determination (R-Square)}

R-Square value for coefficient determination can show influence value of exogenous variable to endogenous variable. The value of R-Square 0.75 denotes a stronger model, 0.50 indicates a moderate model, and 0.25 denotes a weak model. R-Square is only possessed by endogenous variables, that is Training and Education (TRA) with 0.833, Cultural Change (CUL) with 0.723 , Teamwork (TW) with 0.823 , Industrial Infrastructure (ORG) with 0.732 , Six Sigma Success (SS) with 0.950 and Industrial Performance (PER) with 0.826.

\subsubsection{Path coefficient}

The coefficient path can be used to see if the path or relationship between latent variables and other latent variables has an effect on the model. Path or relationship between latent variables must be seen significant level (P-Value) of the influence of the path. The path coefficient should be $>0.100$ with a significance value of 0.05 for the path to be considered 
to have an effect on the model. The value of Path Coefficient $(\beta)$ and significant value (PValue) can be seen in Figure 2. The results show that the path for TW $\rightarrow$ SS, TRA $\rightarrow$ CUL, and TRA $\rightarrow$ TW have negative magnitude so that according to the path coefficient test, it is considered no effect on the model.

\subsubsection{Effect size cohen (f2)}

Cohen Effect Size Testing $\left(\mathrm{f}^{2}\right)$ is used to evaluate the effect of exogenous variables on endogenous variables. The rule of thumb of the value of $\mathrm{f}^{2}$ is 0.02 is considered to have a weak influence, the value of $\mathrm{f}^{2}$ is 0.15 is considered to have medium effect, and the value of $\mathrm{f}^{2}$ is 0.35 is considered to have a strong influence. The following table of values of $\mathrm{f}^{2}$ is related to the relationship between exogenous variables and endogenous variables for critical success factors research model in the application of Six Sigma in Small and Medium Industry in Indonesia (see table III). The results are MAN $\rightarrow$ SS $=0.167$ "sedang", TRA $\rightarrow \mathrm{SS}=0.123$ "sedang", CUL $\rightarrow \mathrm{SS}=0.163$ "sedang", TW $\rightarrow \mathrm{SS}=0.021$ "lemah", ORG $\rightarrow \mathrm{SS}=0.125$ "sedang", $\mathrm{SS} \rightarrow \mathrm{PER}=4.759$ "kuat", MAN $\rightarrow$ TRA $=7.541$ "kuat", MAN $\rightarrow$ CUL $=0.158$ "sedang", MAN $\rightarrow$ TW $=0.161$ "sedang", MAN $\rightarrow$ ORG $=$ 2.731 "kuat", TRA $\rightarrow$ CUL $=0.026$ "lemah", TRA $\rightarrow$ TW $=0.000$ "lemah", and CUL $\mathrm{TW}=0.244$ "sedang"

\subsubsection{Predictive relecance (Q2)}

Predictive relevance $\left(Q^{2}\right)$ represents integration of cross validation and fitting functions with predictions of latent variables and estimates of latent variable indicators. Predictive relevance evaluates whether interrelated latent variables are predicted to have relationships among latent variables. Based on the rule of thumb, $Q^{2}$ with value 0.02 indicates a weak predictive relevance level, 0.15 indicates moderate predictive relevance, and 0.35 indicates strong predictive relevance. Based on SmartPLS software, the value of TRA is 0.881, CUL is 0.712 , TW is 0.813 , ORG is 0.727 , SS is 0.944 , and PER is 0.823 .

\section{Results and discussion}

Based on the result of measurement model and structural model, the path that is formed is: MAN $\rightarrow \mathrm{SS} \rightarrow \mathrm{PER}$ means the involvement and commitment of top management (MAN) has a positive impact on the successful implementation of Six Sigma (SS), and the successful implementation of Six Sigma (SS) has a positive impact on industry performance (PER). MAN $\rightarrow$ TRA $\rightarrow$ SS $\rightarrow$ PER means the involvement and commitment of top management (MAN) has a positive impact on training and education (TRA), then training and education (TRA) has a positive impact on the successful implementation of Six Sigma (SS), and the successful implementation of Six Sigma (SS) has a positive impact on industry performance (PER). MAN $\rightarrow \mathrm{CUL} \rightarrow \mathrm{SS} \rightarrow$ PER means the involvement and commitment of top management (MAN) has a positive impact on cultural change (CUL), then cultural change (CUL) has a positive impact on the successful implementation of Six Sigma (SS), and the successful implementation of Six Sigma (SS) has a positive impact industry performance (PER). MAN $\rightarrow$ ORG $\rightarrow$ SS $\rightarrow$ PER means the involvement and commitment of top management (MAN) have a positive impact on industrial infrastructure (ORG), and industrial infrastructure (ORG) has a positive impact on the successful implementation of Six Sigma (SS), and the successful implementation of Six Sigma (SS) has a positive impact on industry performance (PER). 


\section{Conclusion}

The purpose of this research is to build a model of Six Sigma implementation based on critical success factors, to study the relationship between critical success factors for successful implementation of Six Sigma in small and medium industries in Indonesia, to study the relationship between successful implementation of Six Sigma on the performance of small and medium industries in Indonesia, confirmed the model developed for small and medium industries in Indonesia. The Six Sigma implementation model in this study has 5 latent variables of critical success factors that make Six Sigma successful for implementation, that is top management involvement and commitment, training and education, teamwork, cultural change and industrial infrastructure. There are 4 measuring variables, 3 measuring variables, 3 measuring variables, 3 measuring variables, 3 valid measuring variables representing each critical success factor. While the other two latent variables are the successful application of Six Sigma and latent variables of industry performance are represented by each of the four measuring variables. A total of 13 hypotheses were successfully developed in this study, but only 10 hypotheses were expressed to have a positive impact. The results revealed that four latent variables of critical success factors, namely: involvement and commitment of top management, training and education, cultural change and industrial infrastructure have a positive relationship to the successful implementation of Six Sigma in small and medium industries in Indonesia. And also the successful implementation of Six Sigma has a positive impact to the performance of small and medium industries in Indonesia. In addition, the relationship between critical success factors is also known. It can thus be deduced that if small and medium industries in Indonesia want to achieve success in implementing Six Sigma they must ensure that they have met these critical factors. So the resources they spend in order to implement Six Sigma are not wasted. The limitation of this research is to focus on small and medium industries and the most of the respondents are in manufacturing sector, so the next research is interesting to be done on big industry. In addition, future research can also consider the methods of Analytical Hierarchy Process (AHP), Neural Network, Analytical Network Process (ANP) and Topsis method to be used as a step to follow up the model that has been developed from this research so as to obtain a measurement matrix of success in application of Six Sigma.

\section{Acknowledgement}

This research received funding from the PITTA Grant at Universitas Indonesia.

\section{References}

1. World Bank. (2016). The World Bank. Retrieved Oktober 26, (2017)

2. Bureau of Economic Analysis. (2007). Measuring the Economy: A primer on GDP and the National Income and Product Accounts. Bureau of Economic Analysis, United States Department of Commerce, Economics and Statistics Administration., United States of America.

3. Henderson, J. V., Storeygard, A., \& Weil, D. N. Measuring Economic Growth from Outer Space. American Economi Review , 102 (2), 994-1028. (2012).

4. Central Bereau of Indonesia Statistics. Badan Pusat Statistik. Retrieved September 16, (2017)

5. Antony, J., Kumar, M., \& Madu, C. N. Six sigma in small- and medium-sized UK manufacturing enterprises: Some empirical observations. International Journal of Quality \& Reliability Management , 22 (8), 860-874. (2005) 
6. Demirbag, M., Tatoglu, E., Tekinkus, M., \& Zaim, S. An analysis of the relationship between TQM implementation and organizational performance:Evidence from Turkish SMEs. Journal of Manufacturing Technology Management , 17 (6), 829-847. (2006)

7. Brock, W., \& Evans, D. The Economics of Small Business: Their Roles and Regulations in US Economy. (1986).

8. Kumar, M., Antony, J., Madu, C. N., Montgomery, D. C., \& Park, S. H. Common myths of Six Sigma demystified. International Journal of Quality \& Reliability Management , 25 (8), 878-895. (2008).

9. Ministry of Industry of the Republic of Indonesia. Peraturan Menteri Perindustrian Republik Indonesia Nomor 64 Tahun 2016. (2016).

10. World Economic Forum. World Economic Forum. Retrieved Oktober 26, 2017, (20162017).

11. Kwak, Y. H., \& Anbari, F. T. Benefits, obstacles, and future of six sigma approach. Technovation, 26, 708-715. (2006)

12. Dusharme, D. Six Sigma Survey: Big Success...But What About the other 98 percent? Retrieved January 11, 2018, (2004)

13. Green, K. W., Zelbst, P. J., Meacham, J., \& Bhadauria, V. S. Green supply chain management practices: impact on performance. Supply Chain Management: An International Journal , 17 (3), 290-305. (2012).

14. Coronado, R. B., \& Antony, J. Critical success factors for the successful implementation of six sigma projects in organisations. The TQM Magazine , 14 (2), 9299. (2002)

15. Rungasamy, Antony, \& Ghosh. Critical success factors for SPC implementation. TQM Magazine, 14 (4), 217 - 224. (2002)

16. Pande, P. S., Neuman, R. P., \& Cavanagh, R. R. How GE, Motorola, and Other Top Companies Are Honing Their Performance. The McGraw-Hill Companies, Inc. (2000)

17. Snee, R. D., \& Jr., W. F. The Project Selection Process. Quality Progress , 35 (9), 78 80. (2002)

18. Leong, Tack-Wei., \& Tea, Pei-Lee. Critical Success Factors of Six Sigma in Original Equipment Manufacturer Company in Malaysia. International Journal of Synergy and Research, Vol. 1, No. 1, 7-21. (2012)

19. Henderson, K., \& Evans, J. Successful implementation of Six Sigma: benchmarking general electric company . Benchmarking and International Journal , 7 (4), 260-281. (2000)

20. Sakthivel, P. B., Rajendran, G., \& Raju, R. TQM implementation and students satisfaction of academic performance. The TQM Magazine, 17(6), 573-589. doi: 10.1108/09544780510627660. (2005)

21. Anbari, F.T. and Kwak, Y.H. "Success factors in managing Six Sigma projects", paper presented at the Project Management Institute Research Conference, London, 11-14 July. (2004)

22. Antony, J., \& Banuelas, R. Key ingredients for the effective implementation of Six Sigma program. Measuring Business Excellence , 6 (4), 20-27 (2002)

23. Hayes, B.J, "Six Sigma critical success factors", iSixSigma, (2002)

24. Szeto, A. and Tsang, A. 'Antecedents to successful implementation of Six Sigma', International Journal of Six Sigma and Competitive Advantage, Vol. 1, No. 3, pp.307322 (2005)

25. Coronado, R. B., \& Antony, J. Critical success factors for the successful implementation of six sigma projects in organisations. The TQM Magazine , 14 (2), 92-99 (2002) 
26. Heckl, D., Moormann, J. and Rosemann, M., "Uptake and success factors of Six Sigma in the financial services industry", Business Process Management Journal, Vol. 16, No. 3, pp. 436-472 (2010)

27. Brun, A. Critical success factors of Six Sigma implementations in Italian companies. Int. Journal Production Economics , 131, 158-164 (2010)

28. Rus, I., and Lindvall M. "Knowledge Management in Software Engineering," IEEE Software (19:3), 2002, pp. 26-38.

29. Hurley RF, Hult GTM. Innovation, market orientation, and organiza- tional learning: an integration and empirical examination. J Mark 1998;62:42 - 54.

30. Carvalho, M.M., Ho, L.L. and Pinto, S.H.B., "The Six Sigma program: an empirical study of Brazilian companies", Journal of Manufacturing Technology Management, Vol. 25 No. 5, pp. 602-630 (2014)

31. Brady, J.E. and Allen, T.T., "Six Sigma literature: a review and agenda for future research", Quality and Reliability Engineering International, Vol. 22 No. 3, pp. 335367 (2006)

32. Sohal, A. "Assessing manufacturing or quality culture and practices in Asian companies", International Journal of Quality \& Reliability Management, Vol. 15 No. 8/9, pp. 920-30 (1998)

33. Kundi, O.H.K., "A study of Six Sigma implementation and critical success factors", paper presented at the 9th Pakistan International Convention on Quality Improvement, 14-15 November, Karachi (2005)

34. Chakrabarty, A., \& Tan, K. C. The current state of six sigma application in services . Managing Service Quality: An International Journal , 17 (2), 194-208 (2007).

35. Tlapa, D., Limon, J., García-Alcaraz, J. L., Baez, Y., \& Sánchez, C. Six Sigma enablers in Mexican manufacturing companies: A proposed model. Industrial Management \& Data Systems, 116, 926-959. doi:10.1108/IMDS-06-2015-0265 (2016).

36. $\mathrm{Zu}, \mathrm{X}$., Robbins, T. and Lawrence, F. "Mapping the critical links between organizational culture and TQM/Six Sigma practices", International Journal of Production Economics, Vol. 123 No. 1, pp. 86-106 (2009)

37. Habidin, N. F., \& Yusof, S. M. Critical success factors of Lean Six Sigma for the Malaysian automotive industry . International Journal of Lea n Six Sigma , 4 (1), 6082 (2013).

38. Kaplan, R., \& Norton, D. The Balanced Scorecard: Measures That Drive Performance. Harvard Business Review , 70 (1), 71-79 (1992)

39. Halliday, S. "So what exactly is Six Sigma?"', Works Management, Vol. 54 No. 1, p. 15 (2001)

40. Hair, J., Black, W., Babin, B. and Anderson, R. Multivariate Data Analysis, 7th ed. (electronic edition), Pearson Education Limited, London (2014)

41. Barclay, D.W., Higgins, C.A. and Thompson, R. "The partial least squares approach to causal modeling: personal computer adoption and use as illustration", Technology Studies, Vol. 2 No. 2, pp. 285-309 (1995)

42. Ghozali, I. Structural equation modeling; alternative method with partial least square. Badan Penerbit Universitas Dipenogoro. Semarang (2006)

43. Latan, H dan I. Ghozali. Partial least squares: The concept, technique, and SmartPLS 2.0 M3 application. Badan Penerbit Universitas Dipenogoro. Semarang (2012)

44. Urbach, N., \& Ahlemann, F. Structural equation modeling in information systems research using partial least squares. Journal of Information Technology Theory and Application, 11(2), 5-40 (2010) 